\title{
Genetic evolution of uveal melanoma guides the development of an inflammatory microenvironment
}

\author{
Gülçin Gezgin ${ }^{1}$ Mehmet Dogrusöz ${ }^{1}$ T. Huibertus van Essen ${ }^{1} \cdot$ Wilhelmina G. M. Kroes $^{2}$ • \\ Gregorius P. M. Luyten ${ }^{1}$ Pieter A. van der Velden ${ }^{1}$ - Vonn Walter ${ }^{3} \cdot$ Robert M. Verdijk $^{4} \cdot$ Thorbald van Hall $^{5}$. \\ Sjoerd H. van der Burg ${ }^{5}$ Martine J. Jager ${ }^{1}$
}

Received: 5 September 2016 / Accepted: 20 March 2017 / Published online: 8 April 2017

(c) The Author(s) 2017. This article is an open access publication

\begin{abstract}
Uveal melanoma (UM) is characterized by a number of genetic aberrations that follow a certain chronology and are tightly linked to tumor recurrence and survival. Loss of chromosome 3, bi-allelic loss of BAP1 expression, and gain in chromosome $8 \mathrm{q}$ have been associated with metastasis formation and death, while loss of chromosome 3 has been associated with the influx of macrophages and $\mathrm{T}$ cells. We used a set of genetically-classified UM to study immune infiltration in the context of their genetic evolution. We show in two independent cohorts that lack of BAP1 expression is associated with an increased density of $\mathrm{CD}^{+} \mathrm{T}$ cells and $\mathrm{CD} 8^{+} \mathrm{T}$ cells. The presence of extra copies of chromosome $8 \mathrm{q}$ in disomy 3 tumors with a normal BAP1 expression is associated with an increased influx of macrophages (but not $\mathrm{T}$ cells). Therefore, we propose that the genetic evolution of UM is associated with changes in the inflammatory phenotype. Early changes resulting in gain of chromosome 8q may activate macrophage infiltration, while sequential loss of BAP1 expression seems to drive $\mathrm{T}$ cell infiltration in UM.
\end{abstract}

Martine J. Jager

M.J.Jager@lumc.nl

1 Department of Ophthalmology, Leiden University Medical Center, PO Box 9600, 2300 RC Leiden, The Netherlands

2 Department of Clinical Genetics, Leiden University Medical Center, Leiden, The Netherlands

3 Department of Biochemistry, Penn State Milton S. Hershey Medical Center, Hershey, PA, USA

4 Department of Pathology, Section Ophthalmic Pathology, Erasmus MC University Medical Center, Rotterdam, The Netherlands

5 Department of Clinical Oncology, Leiden University Medical Center, Leiden, The Netherlands
Keywords BAP1 $\cdot$ Infiltration $\cdot$ Macrophages $\cdot \mathrm{T}$ cells . Lymphocytes $\cdot$ Chromosome

\begin{tabular}{|c|c|}
\hline \multicolumn{2}{|c|}{ Abbreviations } \\
\hline$B A P 1$ & BRCA1-associated protein 1 \\
\hline CCL2 & $\begin{array}{l}\text { Chemokine (C-C motif) ligand } 2 \text { (Monocyte } \\
\text { chemoattractant protein-1) }\end{array}$ \\
\hline CCL3 & $\begin{array}{l}\text { Chemokine (C-C motif) ligand } 3 \text { (Macrophage } \\
\text { inflammatory protein } 1 \alpha \text { ) }\end{array}$ \\
\hline CCL5 & Chemokine (C-C motif) ligand 5 (RANTES) \\
\hline CXCL10 & $\begin{array}{l}\text { Chemokine (C-X-C motif) ligand } 10 \text { (Inter- } \\
\text { feron gamma-induced protein } 10 \text { ) }\end{array}$ \\
\hline CXCL12 & $\begin{array}{l}\text { Chemokine (C-X-C motif) ligand } 12 \text { (Stromal } \\
\text { cell-derived factor } 1 \text { ) }\end{array}$ \\
\hline$d P C R$ & Digital polymerase chain reaction \\
\hline$H L A$ & Human leukocyte antigen \\
\hline$I F$ & Immunofluorescence \\
\hline$I H C$ & Immunohistochemistry \\
\hline$N F-\kappa B$ & Nuclear factor $\kappa \mathrm{B}$ \\
\hline$S N P$ & Single-nucleotide polymorphism \\
\hline TCGA & The Cancer Genome Atlas \\
\hline$U C H$ & Ubiquitin-carboxy-terminal hydrolase \\
\hline UCHL1 & Ubiquitin carboxyl-terminal hydrolase L1 \\
\hline UCHL2 & Ubiquitin carboxyl-terminal hydrolase L2 \\
\hline$U M$ & Uveal melanoma \\
\hline$V E G F A$ & Vascular Endothelial Growth Factor A \\
\hline
\end{tabular}

\section{Introduction}

Uveal melanoma (UM) is the most common primary intraocular malignancy in Caucasian adults and may lead to metastatic disease in up to $50 \%$ of patients $[1,2]$. Current treatments are hardly ever effective against metastases [3], and hence, most research efforts are focused on the 
development of targeted therapies or immunotherapeutic approaches, such as treatments with immune checkpoint inhibitors, vaccination, or adoptive $\mathrm{T}$ cell therapy [4-8].

Some UM express increased levels of human leukocyte antigen (HLA) class I and are infiltrated by macrophages and lymphocytes, and this is known as an inflammatory phenotype [9-12]. The presence of this inflammatory phenotype has been correlated with a specific genetic aberration, which is the loss of one copy of chromosome 3 (monosomy 3) [13]. Other chromosomal abnormalities frequently occur in chromosomes 1, 6, and 8 [14-17]. Following an initiating mutation in either GNAQ or GNA11, gain of $8 \mathrm{q}$ is thought to be one of the earliest genetic aberrations, followed by loss of one chromosome $3[18,19]$. Gain of $8 \mathrm{q}$ and monosomy 3 and are both associated with the development of UM metastases and a poor prognosis [16, 20]. Similarly, gene expression analysis has been used to divide UM into two major classes, 1 and 2, which are good predictors of prognosis [21, 22]. Moreover, we recently showed that, in our hands, class II tumors can be subdivided into IIa and IIb: while class IIa tumors are composed of highly homogeneous tumor cells and class IIb tumors contain a larger percentage of non-tumor cells which are likely to be immune cells. Interestingly, class IIa and IIb tumors differed in their numbers of chromosome 8q copies [19].

Chromosome 3 contains the gene for BRCAl-associated protein 1 (BAP1). In UM, inactivating hemizygous mutations in this gene have been found [23, 24], which are associated with loss of BAP1 protein expression and a high metastatic risk [23-26]. However, monosomy 3 and loss of BAP1 may occur independently, as tumors with a normal chromosome 3 status with lack of BAP1 expression have been identified, as well as tumors with monosomy 3 that still express BAP1. Such atypical tumors show highrisk clinico-pathological features and convey an increased metastatic risk [25]. BAP1 is a member of the ubiquitincarboxy-terminal hydrolase (UCH) family [27], and is also known as ubiquitin carboxyl-terminal hydrolase L2 (UCHL2). Another member of the UCH family, ubiquitin carboxyl-terminal hydrolase L1 (UCHL1), is associated with suppressed production of pro-inflammatory chemokines and cytokines in keratinocytes [28]. We, therefore, hypothesized that loss of BAP1 expression might be related to macrophage and/or T cell infiltration.

To assess whether genetic alterations affect immune cell infiltration in UM, we studied the presence and type of tumor-infiltrating immune cells in UM subtypes consisting of typical cases of UM (e.g. disomy 3 tumors with BAP1 expression and monosomy 3 with loss of BAP1 expression) and atypical cases of UM (e.g. disomy 3 tumors with loss of BAP1 expression and monosomy 3 tumors with expression of BAP1). In addition, we studied disomy 3/BAP1-positive cases with and without extra copies of chromosome 8q.
Our data show that loss of BAP1 protein expression is predominantly related to $\mathrm{T}$ cell infiltration in UM, while early gain of chromosome $8 \mathrm{q}$ is associated with macrophage infiltration.

\section{Materials and methods}

\section{Patient selection}

Tumor tissue specimens were obtained from 84 UM patients. Patients underwent primary enucleation for UM between 1999 and 2008 at the Leiden University Medical Center (Leiden, The Netherlands). Part of the tumor was snap frozen using 2-methyl butane, and DNA and RNA were isolated. The remaining tumor was fixed in $4 \%$ neutral-buffered formalin for $48 \mathrm{~h}$ and subsequently embedded in paraffin. This study was approved by the Medical Ethics Committee of the Leiden University Medical Center. Tumor material was handled according to the Dutch National Ethical Guidelines ('Code for Proper Secondary Use of Human Tissue'), and the tenets of the Declaration of Helsinki (World Medical Association of Declaration 2013; ethical principles for medical research involving human subjects). In addition, 80 patients from The Cancer Genome Atlas (TCGA) Project on UM were included in this study as an independent validation cohort.

\section{Immunohistochemistry and fluorescent immunostaining of the Leiden Cohort}

4- $\mu \mathrm{m}$ serial sections from paraffin-embedded tissue were cut and used for immunostaining. Immunohistochemistry (IHC) of BAP1 was performed on 74 tumors, as described previously [24]. Tumors were scored by two independent investigators as BAP1-positive or -negative based on nuclear staining. Immunofluorescence (IF) staining for $\mathrm{T}$ cells and macrophages was performed on 43 tumors as described previously $[29,30]$. T cell types were detected by primary antibodies: anti-CD3 (ab828, rabbit polyclonal; Abcam, Cambridge, MA, United States of America) and anti-CD8 (4B11, mouse monoclonal IgG2b; Novocastra, Valkenswaard, The Netherlands). To visualize the T cells, the following secondary antibodies were used: goat-antirabbit IgG Alexa 546 and goat-anti-mouse IgG2b Alexa 647 (Molecular Probes, Invitrogen, Breda, The Netherlands). Counts of intratumoral $\mathrm{CD}^{+}$and $\mathrm{CD}^{+} \mathrm{T}$ cells were represented as the number of cells per square millimeter. For IF staining of $\mathrm{CD}^{+} 8^{+}$macrophages, we used the primary mouse anti-human macrophage CD68 antibody (clone 514H12; ab49777; Abcam, Cambridge, United Kingdom), and as secondary antibody AlexaFluor IgG2a 
(488) goat-anti-mouse. The amount of $\mathrm{CD}^{+} 8^{+}$expression was determined in pixels per square millimeter.

\section{DNA and gene expression analysis}

DNA and gene expression analysis were performed on 54 tumor specimens from Leiden, in which the BAP1 status was known. The QIAmp DNA Mini kit was used to isolate DNA for single-nucleotide polymorphism (SNP) analysis (Qiagen, Venlo, The Netherlands). SNP analysis was then performed with the Affymetrix 250K_NSP microarray and Affymetrix Cytoscan HD chip (Affymetrix, Santa Clara, California, United States of America) to detect aberrations of chromosome 3 as described previously [20]. Information on chromosome $8 \mathrm{q}$ was obtained by digital polymerase chain reaction (dPCR) [20]. A threshold of $>2.1$ was defined as having extra copies of chromosome 8q. The RNeasy mini kit was used to isolate RNA for gene expression analyses (Qiagen, Venlo, The Netherlands). Gene expression levels of $C D 3$ and $C D 8$ (T cells), $C D 68$ (macrophages), and pro-inflammatory cytokines, specifically macrophage inflammatory protein $1 \alpha$ (CCL3), vascular endothelial growth factor A (VEGFA), stromal cell-derived factor 1 (CXCL12), CCL7, CSF-1, monocyte chemoattractant protein-1 (CCL2), RANTES (CCL5), interferon gamma-induced protein 10 (CXCL10), CCR7, and CXCR4 were obtained using the Illumina HT-12 v4 chip (Illumina, San Diego, California, United States of America). The proinflammatory cytokines were selected based on our previous papers [31-33]. We could validate the probes for $C D 3$, $C D 8$ and $C D 68$ in 24 tumors in which gene expression levels had been determined with an Illumina HT12 v4 array and in which the number of infiltrating cells was analyzed by IF. In addition, data on RNA sequencing and Affymetrix SNP 6.0 array from 80 samples of UM were obtained from the TCGA Research Network: http://cancergenome. nih.gov/. Copy numbers for 8q were determined by Affymetrix SNP 6.0 array and analyzed with the GISTIC 2.0 algorithm $[34,35]$. Copy numbers $>2$ were categorized as extra copies of chromosome 8q. BAP1, CD68, CD3, and $C D 8$ expression were obtained by RNA sequencing and quantified as $\log 2(\mathrm{RSEM}+1)$. $B A P 1$ expression was dichotomized into $B A P l$-positive and $B A P l$-negative expression at the median.

\section{Statistical analysis}

Analyses were performed using SPSS version 20.0.0 (IBM SPSS Statistics, IBM Corporation, Armonk, New York, United States of America) and graphs were made using GraphPad Prism version 5.0 for Windows (GraphPad Software, La Jolla, California, United States of America, http:// www.graphpad.com). The Mann-Whitney $U$ test was applied for continuous parameters. Correlation analyses were performed with Spearman's rho correlation test. A $P$ value $<0.05$ was considered statistically significant.

\section{Results}

\section{Loss of BAP1-protein expression is associated with an inflammatory phenotype in UM}

As expression of UCHL1, a member of the UCH family, has been associated with suppression of pro-inflammatory cytokines and chemokines in keratinocytes [28], we determined whether loss of expression of another UCH-member, BAP1 might be correlated to the development of an inflammatory phenotype in UM. We quantified the number of tumor-infiltrating macrophages and $\mathrm{T}$ cells by immunofluorescence staining of tissue sections in a cohort of 20 BAP1-immunopositive tumors and 23 BAP1-immunonegative tumors from the Leiden cohort, and found that BAP1negative tumors contained significantly higher numbers of $\mathrm{CD}^{+} \mathrm{T}$ cells $(P=0.002), \mathrm{CD} 8^{+} \mathrm{T}$ cells $(P=0.003)$, and $\mathrm{CD} 8^{+}$macrophages $(P<0.001)$ (Fig. 1a-b).

To corroborate our findings, we analyzed gene expression array data from 54 cases of UM in which BAP1 expression as well as chromosome 3 and $8 \mathrm{q}$ status had been determined. We first correlated potentially-useful probes by comparing IF staining data for $\mathrm{CD}^{+} 8^{+}$macrophages, $\mathrm{CD}^{+}$and $\mathrm{CD}^{+}{ }^{+} \mathrm{T}$ cells with their corresponding CD68, $\mathrm{CD} 3$, and $\mathrm{CD} 8$ probes used for RNA gene expression analysis in a group of 24 patients for whom both tests were available. The probes with the highest correlation were used for further analyses (Table 1), since we assumed that these probes represent the corresponding protein expression most accurately. We subsequently compared the presence of specific probes with BAP1 expression: a higher expression of $C D 3(P=0.016), C D 8(P=0.015)$, and $C D 68$ $(P=0.002)$ was observed in tumors that did not express BAP1 $(n=24)$ compared to tumors that did express BAP1 ( $n=30$; Fig. 1c), corroborating our results obtained with IF staining (Fig. 1a, b). These results indicate that loss of BAP1 expression in UM is associated with a higher T cell and macrophage infiltration.

Since most monosomy 3 tumors lack BAP1 expression, it is difficult to determine whether the effects observed are due to loss of BAP1 expression or due to loss of one chromosome 3 . We therefore, focused on atypical cases, and observed that within the disomy 3 tumors, loss of BAP1 protein expression was associated with increased numbers of $\mathrm{CD}^{+} \mathrm{T}$ cells $(P=0.036), \mathrm{CD} 8^{+} \mathrm{T}$ cells $(P=0.018)$ and $\mathrm{CD}^{+} 8^{+}$macrophages $(P=0.018)$. Within the monosomy 3 tumors, we noticed that the expression of BAP1 protein was associated with significantly lower 

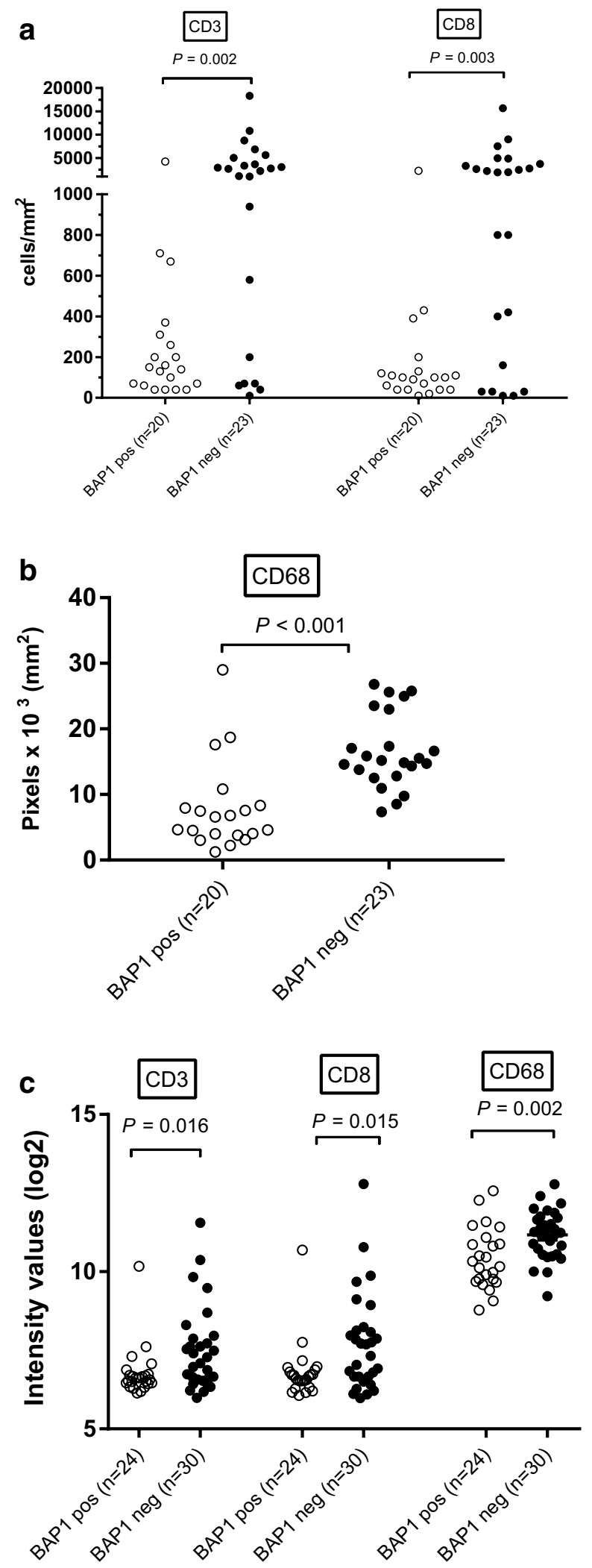

Fig. 1 Presence of T cells (a), and macrophages (b) as determined by IF staining or by gene expression (c) was compared between BAP1positive and BAP1-negative tumors from the Leiden cohort
Table 1 Correlation of the values of different probes obtained with an Illumina gene expression array with immunohistochemical data in the Leiden cohort

\begin{tabular}{llllc}
\hline T cell type & Probe name & Probe number & $\mathrm{R}$ & $P$ value \\
\hline CD68 $(n=24)$ & CD68 probe 1 & ILMN_1714861 & $\mathbf{0 . 4 9 0}$ & $\mathbf{0 . 0 1 5}$ \\
& CD68 probe 2 & ILMN_2359907 & 0.372 & 0.073 \\
& CD68 probe 3 & ILMN_2267914 & 0.252 & 0.235 \\
CD3 $(n=24)$ & CD3D probe 1 & ILMN_2261416 & $\mathbf{0 . 7 6 0}$ & $<\mathbf{0 . 0 0 1}$ \\
& CD3D probe 2 & ILMN_2325837 & 0.748 & $<0.001$ \\
& CD3E & ILMN_1739794 & 0.523 & 0.009 \\
CD8 $(n=24)$ & CD3G & ILMN_1717197 & 0.622 & 0.001 \\
& CD8A probe 1 & ILMN_1768482 & 0.685 & $<0.001$ \\
& CD8A probe 2 & ILMN_1760374 & 0.500 & 0.013 \\
& CD8A probe 3 & ILMN_2353732 & $\mathbf{0 . 7 4 4}$ & $<\mathbf{0 . 0 0 1}$ \\
& CD8B probe 1 & ILMN_1748601 & 0.126 & 0.558 \\
& CD8B probe 2 & ILMN_2354191 & 0.388 & 0.061 \\
\hline
\end{tabular}

The highest correlated probes (in bold) were used for further analysis $P$ values were obtained by the Spearman's Rho correlation test $n$ number of patients, $R$ correlation coefficient

numbers of $\mathrm{CD}^{+} \mathrm{T}$ cells $(P=0.034)$ and $\mathrm{CD} 8^{+} \mathrm{T}$ cells $(P=0.034)$, but not of $\mathrm{CD}^{+} 8^{+}$macrophages $(P=0.11$; Fig. 2a-b). This shows that in disomy 3 as well as monosomy 3 tumors, the loss of BAP1 protein is associated with more infiltrating $\mathrm{T}$ cells.

In addition, we scrutinized an independent cohort that was available from the TCGA for a potential association between the BAP1-status and infiltration with T cells and macrophages. $B A P I$-negative tumors showed a higher expression of $C D 3(P<0.001)$ and $C D 8(P<0.001)$, but not for $C D 68(P=0.149)$ than $B A P 1$-positive tumors (Fig. 3), which confirms our finding that loss of BAP1 is associated with a higher density of T cells in UM.

Immune cell infiltration of tumors is governed by the local production of cytokines and chemokines. We analyzed whether the expression of several cytokines and chemokines involved in $\mathrm{T}$ cell and macrophage chemotaxis differed between 24 BAP1-positive and 30 BAP1negative tumors from the Leiden cohort [31, 32]. Gene expression of CCL5 and CXCL10, important chemokines in $\mathrm{T}$ cell chemotaxis, was higher in the BAP1-negative tumors $(P<0.001 ; P=0.005$ and $P=0.065$; Table $2 \mathrm{a})$.

Altogether, these results show that the production of immune cell-attracting chemokines and infiltration of different types of immune cells in UM are associated with the loss of BAP1 expression, independent of chromosome 3 loss. 

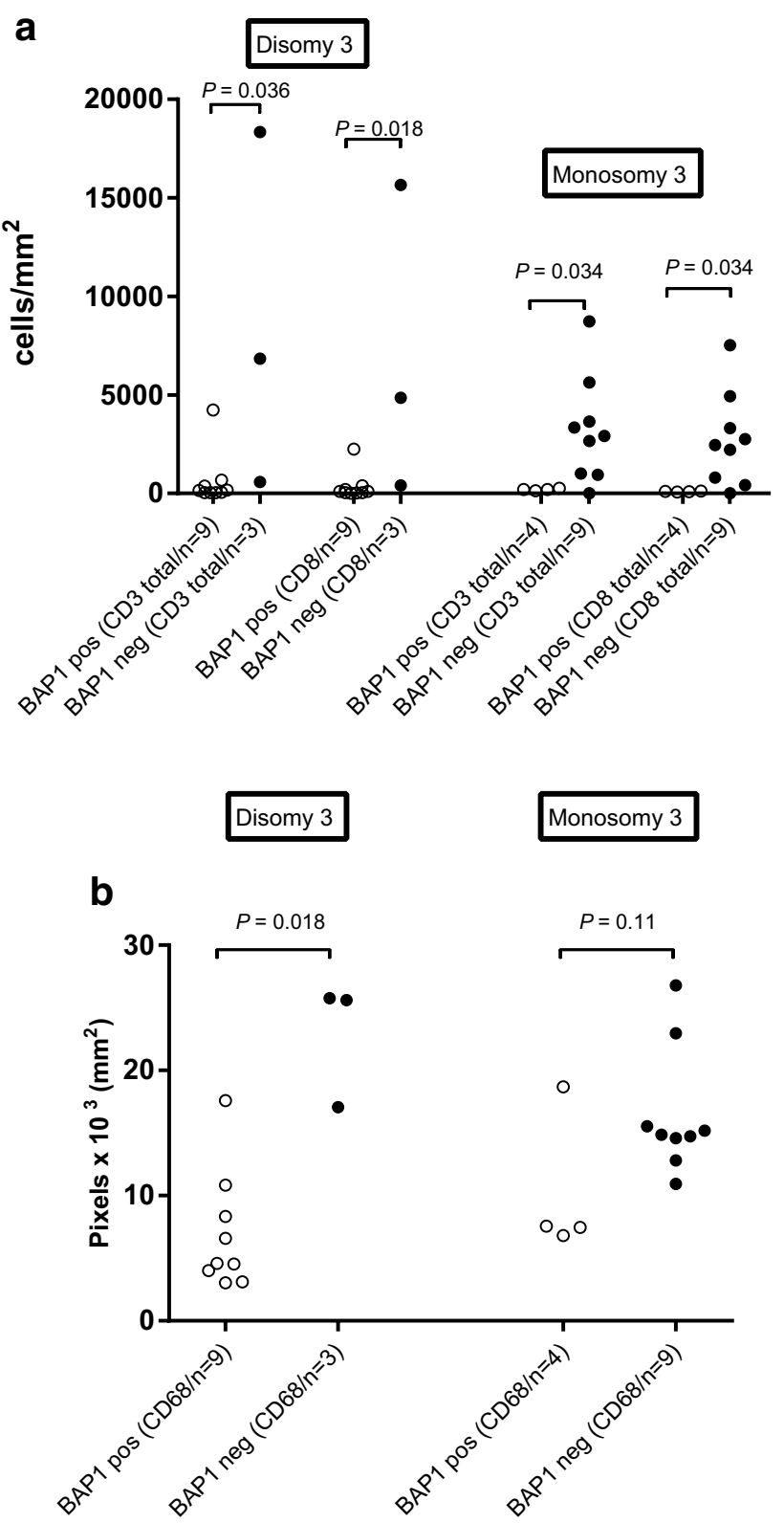

Fig. 2 Comparison of T cells (a) and macrophages (b) as determined by IF staining between BAP1-positive and BAP1-negative tumors from the Leiden cohort that were either disomic or monosomic for chromosome 3 according to the Mann-Whitney $U$ test

\section{Influence of chromosome 8q gain on the inflammatory microenvironment}

Gain in the copy number of chromosome $8 \mathrm{q}$ is considered an early event in UM development, occurring before loss of chromosome $3[18,19]$. Seventeen cases of UM from Leiden were available in which the tumor showed gain in chromosome 8q but did not show loss of chromosome 3 or lack of BAP1 protein expression. These cases allowed us to study the influence of gain of chromosome $8 \mathrm{q}$ on immune cell infiltration. Tumors that carried additional copies of chromosome $8 \mathrm{q}$ had an increased expression of $C D 68(P=0.006)$, but not of $C D 3$ and $C D 8$ (Fig. 4). Again, using the TCGA data as an independent cohort, we analyzed whether there was an association between gain of chromosome 8q and the presence of macrophages and $\mathrm{T}$ cells. BAP1-positive tumors with extra copies of $8 \mathrm{q}$ had an increased expression of $C D 68(P<0.001)$ (Fig. 3) but not of $C D 3$ or $C D 8$ compared to $B A P 1$-positive tumors with a normal chromosome 8q. Since these tumors had no loss of chromosome 3 or aberrant expression of BAP1, these data confirm our finding in the Leiden cohort that the early gain in chromosome $8 \mathrm{q}$ is responsible for macrophage infiltration but not for $\mathrm{T}$ cell infiltration.

In addition, we determined whether, in the disomy $3 /$ BAP1-positive tumors from the Leiden cohort, extra copies of chromosome 8q affect the expression of pro-inflammatory cytokines. The myeloid-cell attracting chemokines $C C L 3$ and $C C L 2$ showed a higher expression in disomy3/ BAP1-positive tumors $(P=0.002$ and $P=0.059$, respectively) that carried extra copies of chromosome $8 \mathrm{q}$ than did disomy3/BAP1-positive tumors with two copies of chromosome $8 \mathrm{q}$ (Table $2 \mathrm{~b}$ ). This was not the case for the expression of typical T cell attracting chemokines, such as CCL5, CXCL12, and CXCL10.

\section{Discussion}

We show that the presence of extra copies of chromosome $8 \mathrm{q}$ in UM is associated with macrophage infiltration, while loss of BAP1 protein expression, with or without loss of chromosome 3 , is associated with $\mathrm{T}$ cell infiltration in UM.

The chromosomal evolution of aggressive UM is thought to start with a mutation in GNAQ/GNA11 [36, 37], followed by gain of chromosome $8 \mathrm{q}$ that precedes a potential loss of one copy of chromosome 3 and/or mutation in the $B A P 1$ gene $[20,38]$. We show that in UM with disomy 3 and expression of BAP1, the presence of additional copies of chromosome $8 \mathrm{q}$ is highly associated with the increased expression of macrophage-attracting chemokines and a stronger macrophage infiltration. In this subgroup, no effect was found with respect to the production of chemokines associated with $\mathrm{T}$ cell infiltration. This phenomenon could not be assessed in monosomy 3 tumors as more than $90 \%$ of monosomy $3 \mathrm{UM}$ carry extra copies of $8 \mathrm{q}$. Thus, a gain in copy number of chromosome $8 \mathrm{q}$ is associated with an increase in macrophage infiltration.

One might expect that this influx is initiated by activation of the c-Myc gene, a proto-oncogene located on chromosome $8 \mathrm{q} 24$, which is upregulated in many types of cancer and has been studied in UM [18, 39, 40]. It has previously been suggested that c-Myc may be involved in the 
Fig. 3 Comparison of $\mathrm{T}$ cells and macrophages as determined by gene expression between tumors from the TCGA cohort with a normal and abnormal chromosome 8q status in cases that had low (BAPl-negative) or high (BAP1-positive) $B A P 1$ expression as determined by RNA sequencing

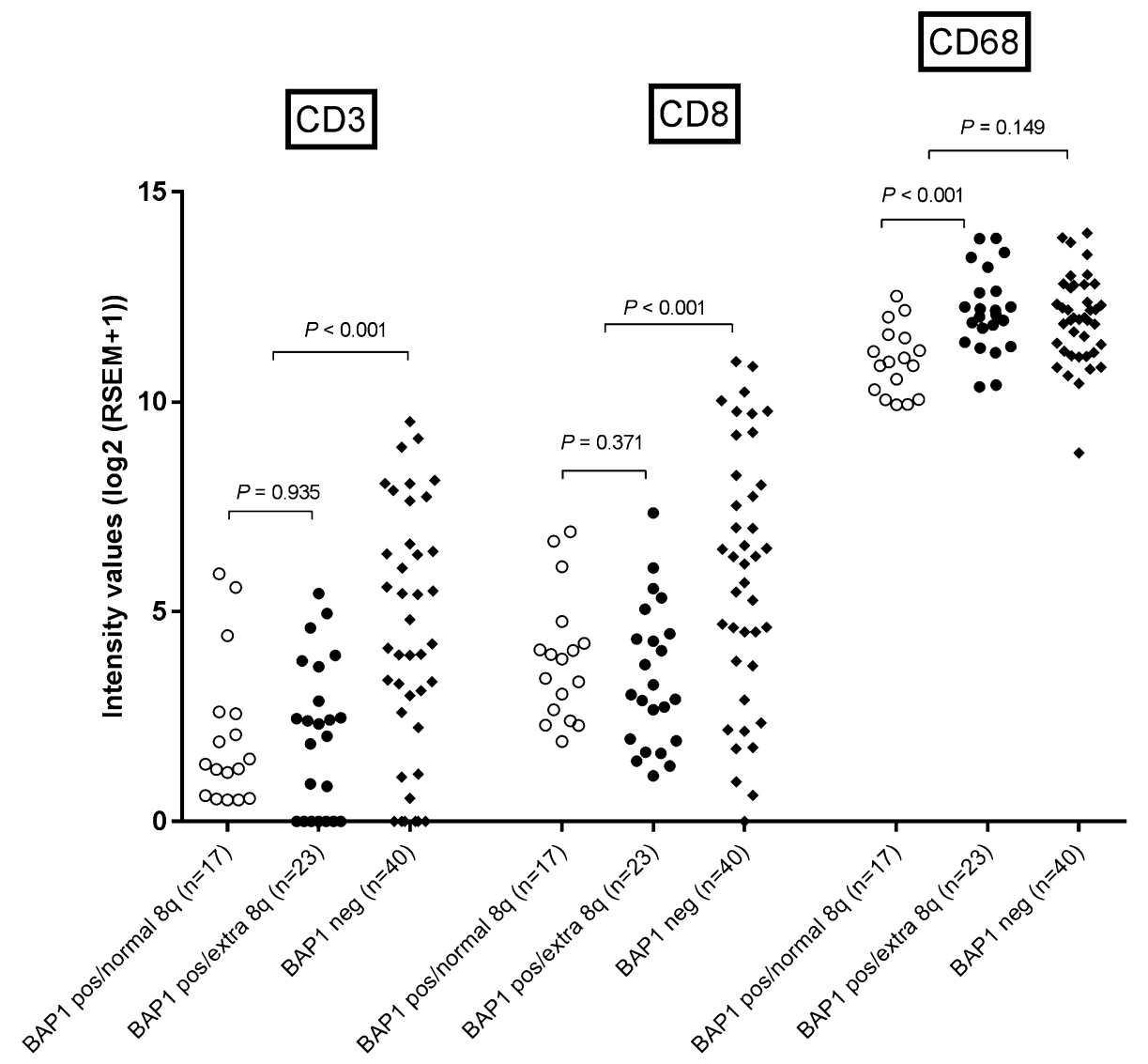

activation of inflammatory mediators in the tumor microenvironment [41]. However, we previously observed the opposite, i.e., an association between a high c-Myc expression and a low inflammatory phenotype, making it unlikely that c-Myc is the relevant factor [42].

Monosomy 3 and loss of BAP1-protein expression are strongly correlated in UM, but we observed several atypical cases which allowed us to separately assess the contribution of chromosome 3 and BAP1-protein expression on the magnitude and type of immune cell infiltration and to pinpoint that it was the loss of BAP1 which was associated with the higher expression of T cell-attracting chemokines and a stronger $\mathrm{T}$ cell infiltration in UM. The previous studies have reported that tumor suppressor proteins can be involved in the processes and pathways of tumor-promoting inflammation by interacting with transcription factors

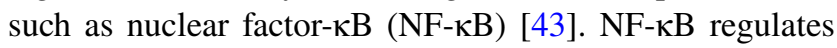
genes which are involved in inflammation and immune responses. A close family member of BAP1 is UCHL1. Similar to BAP1, UCHL1 functions as a tumor suppressor protein [44] and was recently shown to suppress the NF-KB pathway, thereby negatively affecting the production of type 1 interferon and pro-inflammatory cytokines and chemokines, including CCL5 [28]. We, therefore, hypothesize that BAP1 may have a similar function as UCHL1 and that loss of BAP1 alleviates the suppression pathways leading to activation of NF- $\kappa \mathrm{B}$, resulting in the production of cytokines and chemokines that attract tumorspecific T cells into UM.

Obvious correlations between genetic changes and the development of an immune infiltrate are not easy to find. Loss of function of several tumor suppressor genes ( $p 53$, $P T E N)$ due to genetic aberrations is known to be associated with inflammation [45]. Interestingly, loss of BAP1 in an unusual cutaneous tumor, the atypical Spitz nevus, was associated with a higher presence of T cells [46].

When looking at UM, one of the chemokines that was higher in BAP1-negative than BAP1-positive tumors was CCL5; another chemokine that was almost significantly higher in BAP1-negative tumors was CXCL10. CCL5 and CXCL10 play a role in the recruitment of T cells [47]. An influence of BAP1 on NF- $\mathrm{KB}$ and the additional release of pro-inflammatory multifunctional chemokines might explain why both macrophages and $\mathrm{T}$ cells are found in BAP1-negative UM, but this requires further research.

Another chemokine involved in $\mathrm{T}$ cell recruitment is CXCL12, which is the ligand for chemokine receptor CXCR4. Previously, it has been described that CXCR4 is 
Table 2 Expression of pro-inflammatory chemokines and receptors in BAP1-positive and BAP1-negative UM (a), and in disomy 3/BAP1-positive tumors, with and without $8 \mathrm{q}$ gain $(\mathbf{b})$ in the Leiden cohort

\begin{tabular}{|c|c|c|c|}
\hline (a) & BAP1-positive $(n=24)$ & BAP1-negative $(n=30)$ & $P$ value $^{+}$ \\
\hline CCL3 (MIP-1 $\alpha)$ & $6.7(6.5-8.5)$ & $6.7(6.3-8.0)$ & 0.321 \\
\hline VEGFA probe 1 & $6.8(6.5-7.4)$ & $6.8(6.5-7.3)$ & 0.651 \\
\hline VEFGA probe 2 & $6.4(6.3-6.8)$ & $6.4(6.2-6.8)$ & 0.403 \\
\hline CXCL12 (SDF-1) probe 1 & $7.1(6.6-8.6)$ & $7.3(6.5-9.4)$ & 0.689 \\
\hline CXCL12 (SDF-1) probe 2 & $6.6(6.3-7.1)$ & $6.6(6.3-7.6)$ & 0.175 \\
\hline CXCL12 (SDF-1) probe 3 & $6.5(6.2-7.1)$ & $6.5(6.0-7.3)$ & 0.848 \\
\hline CCL7 & $6.2(6.0-6.5)$ & $6.3(5.9-6.7)$ & 0.088 \\
\hline CSF-1 & $6.4(6.3-6.7)$ & $6.5(6.3-6.7)$ & 0.130 \\
\hline CCL2 (MCP-1) & $7.2(6.4-9.5)$ & $7.1(6.4-9.1)$ & 0.614 \\
\hline CCL5 (RANTES) probe 1 & $6.9(6.4-10.7)$ & $7.5(6.5-12.1)$ & $<0.001$ \\
\hline CCL5 (RANTES) probe 2 & $7.7(6.6-12.4)$ & $8.8(7.0-14.4)$ & 0.005 \\
\hline CXCL10 (IP-10) & $6.8(6.4-10.5)$ & $7.4(6.4-10.4)$ & 0.065 \\
\hline CCR7 & $6.4(6.1-7.0)$ & $6.3(6.0-7.2)$ & 0.903 \\
\hline CXCR4 probe 1 & $6.5(6.2-7.2)$ & $6.7(6.2-8.3)$ & 0.038 \\
\hline CXCR4 probe 2 & $6.5(6.1-6.9)$ & $6.4(6.2-6.8)$ & 0.010 \\
\hline CXCR4 probe 3 & $6.6(6.2-7.5)$ & $6.8(6.2-8.2)$ & 0.216 \\
\hline (b) & $\mathrm{D} 3 / \mathrm{BAP} 1+/ \mathrm{n} 8 \mathrm{q}(n=9)$ & $\mathrm{D} 3 / \mathrm{BAP} 1+/ 8 \mathrm{q}$ gain $(n=8)$ & $P$ value* \\
\hline CCL3 (MIP-1 $\alpha$ ) & $6.6(6.5-6.8)$ & $6.8(6.7-8.1)$ & 0.002 \\
\hline VEGFA probe 1 & $6.7(6.5-6.9)$ & $6.9(6.6-7.4)$ & 0.059 \\
\hline VEFGA probe 2 & $6.4(6.3-6.6)$ & $6.5(6.3-6.8)$ & 0.236 \\
\hline CXCL12 (SDF-1) probe 1 & $7.1(6.7-7.9)$ & $7.1(6.6-8.6)$ & 0.743 \\
\hline CXCL12 (SDF-1) probe 2 & $6.5(6.3-6.8)$ & $6.5(6.4-6.8)$ & 0.743 \\
\hline CXCL12 (SDF-1) probe 3 & $6.5(6.3-6.7)$ & $6.5(6.2-7.0)$ & 0.888 \\
\hline CCL7 & $6.1(6.0-6.3)$ & $6.3(6.1-6.4)$ & 0.277 \\
\hline CSF-1 & $6.4(6.3-6.6)$ & $6.4(6.3-6.6)$ & 0.606 \\
\hline CCL2 (MCP-1) & $6.8(6.4-7.7)$ & $7.3(6.8-9.1)$ & 0.059 \\
\hline CCL5 (RANTES) probe 1 & $6.8(6.4-7.0)$ & $6.9(6.5-7.5)$ & 0.236 \\
\hline CCL5 (RANTES) probe 2 & $7.4(6.6-8.2)$ & $7.9(7.0-8.9)$ & 0.277 \\
\hline CXCL10 (IP-10) & $6.7(6.4-7.4)$ & $6.8(6.5-8.4)$ & 0.321 \\
\hline CCR7 & $6.3(6.1-6.6)$ & $6.4(6.2-6.7)$ & 0.606 \\
\hline CXCR4 probe 1 & $6.4(6.2-6.7)$ & $6.5(6.3-6.9)$ & 0.114 \\
\hline CXCR4 probe 2 & $6.5(6.1-6.6)$ & $6.5(6.2-6.9)$ & 0.370 \\
\hline CXCR4 probe 3 & $6.5(6.2-6.9)$ & $6.6(6.3-7.3)$ & 0.321 \\
\hline
\end{tabular}

The boldface indicates a significant difference

$D 3$ disomy 3, $B A P 1+$ positive BAP1 protein expression, $n 8 q$ normal chromosome $8 \mathrm{q}$ status, $8 q$ gain chromosome $8 \mathrm{q}$ gain, $n$ number of patients; median (range)

${ }^{+} P$ value comparison of chemokine expression in BAP1-positive and BAP1-negative tumors

* $P$ value comparison of chemokine expression in tumors with D3/BAP1+/n8q and tumors with D3/BAP1+/8q gain

involved in the migration of UM cells to the liver [48, 49]. In contrast, another group reported that the expression of CXCR4 was, indeed, correlated with lymphocyte infiltration, but had no prognostic relevance in UM patients [33]. We observed discrepant results for CXCR4 in our Leiden cohort, with one probe showing a higher expression in BAP1-negative tumors, and another one a lower expression (Table 2a).
Previously, it had been shown that tumor-intrinsic active $\beta$-catenin signaling restrains tumor-infiltration by $\mathrm{T}$ cells, resulting in the escape of tumors from immune surveillance [50]. The $\beta$-catenin protein is encoded by the gene $C T N N B 1$, which, like $B A P 1$, is located on chromosome $3 \mathrm{p} 21$. Hence, loss of chromosome 3 may also reduce $\beta$-catenin expression. In contrast to BAPI [24, 25], however, there is no evidence that the other allele of $C T N N B 1$ is frequently mutated in UM and thus that the loss of 


\section{Disomy 3/BAP1-positive UM}

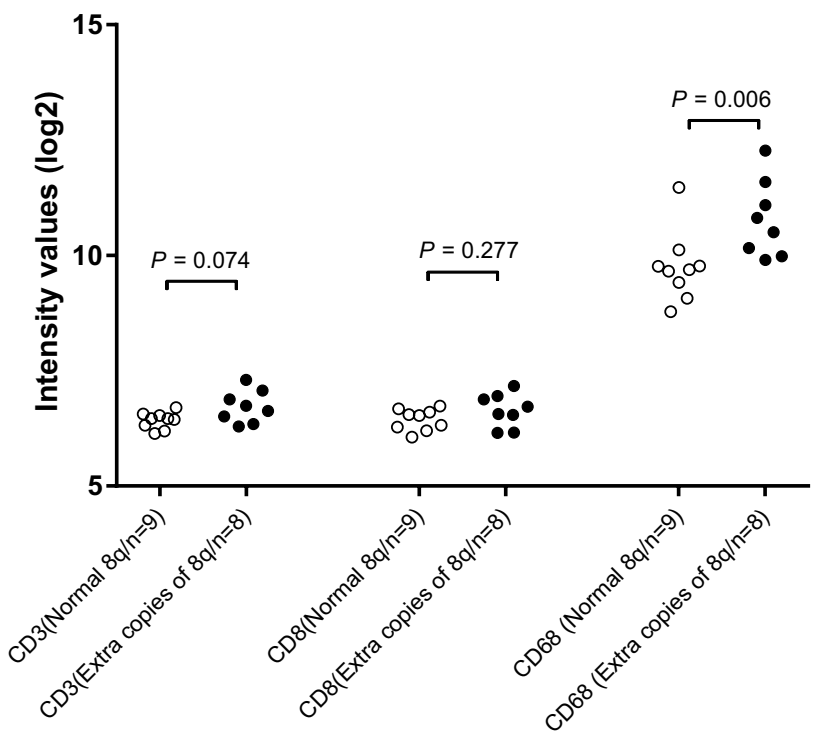

Fig. 4 Comparison of $\mathrm{T}$ cells and macrophages as determined by gene expression between tumors from the Leiden cohort with a normal and abnormal chromosome 8q status in cases that were disomic for chromosome 3 and BAP1-positive as determined by IHC staining

$\beta$-catenin signalling is underlying T cell infiltration in UM. In our cohort, we found no correlation between CTNNBI expression and the amount of $\mathrm{CD}^{+} \mathrm{T}$ cells. Furthermore, the number of $\beta$-catenin-positively staining tumor cells in $\mathrm{UM}$ is around $10 \%$ [51], making its expression an unlikely explanation for the absence of $\mathrm{T}$ cell infiltration in most UM.

Our current findings show that alterations in copy numbers or mutations in certain genes can drive a specific type of immune response. As the most common treatment of UM is irradiation and not enucleation, we wondered whether local treatments might affect immune infiltration in UM. No tumors in either the Leiden cohort or the TCGA cohort had received prior irradiation. A previous study from our group showed that more $\mathrm{T}$ cells were present in secondarily enucleated eyes after prior irradiation compared to primarily enucleated eyes [52]. As irradiation influenced our chromosome testing, we could not always analyze the chromosome status in previously irradiated tumors [53]. We do not yet know how the type of inflammation or irradiation influences the patient's response to immunotherapy, which at this moment has not been very successful in UM.

In conclusion, we provide evidence that the magnitude and type of immune cell infiltration observed in the subgroup of inflamed UM co-evolve with the sequential genetic changes occurring in UM. The initial infiltration by macrophages is related to a gain in the copy number of chromosome 8q, while additional $\mathrm{T}$ cell infiltration is correlated to a loss of functional BAP1-protein expression.

Acknowledgements This project was supported by Algemene Nederlandse Vereniging Ter Voorkoming van Blindheid (ANVVB), Stichting Blinden Penning, Landelijke Stichting voor Blinden en Slechtzienden (LSBS), Novartis Foundation, Stichting Nederlands Oogheelkundig Onderzoek (SNOO), Rotterdamse Stichting Blindenbelangen, and the European Union Horizon 2020 program UM Cure (Project number: 667787).

\section{Compliance with ethical standards}

Conflict of interest The authors declare that they have no conflict of interest.

Open Access This article is distributed under the terms of the Creative Commons Attribution 4.0 International License (http:// creativecommons.org/licenses/by/4.0/), which permits unrestricted use, distribution, and reproduction in any medium, provided you give appropriate credit to the original author(s) and the source, provide a link to the Creative Commons license, and indicate if changes were made.

\section{References}

1. Kujala E, Makitie T, Kivela T (2003) Very long-term prognosis of patients with malignant uveal melanoma. Invest Ophthalmol Vis Sci 44:4651-4659

2. Kaliki S, Shields CL (2016) Uveal melanoma: relatively rare but deadly cancer. Eye (Lond). doi:10.1038/eye.2016.275

3. Augsburger JJ, Correa ZM, Shaikh AH (2009) Effectiveness of treatments for metastatic uveal melanoma. Am J Ophthalmol 148:119-127. doi:10.1016/j.ajo.2009.01.023

4. Hodi FS, O'Day SJ, McDermott DF et al (2010) Improved survival with ipilimumab in patients with metastatic melanoma. $\mathrm{N}$ Engl J Med 363:711-723. doi:10.1056/NEJMoa1003466

5. Larkin J, Chiarion-Sileni V, Gonzalez R et al (2015) Combined Nivolumab and Ipilimumab or Monotherapy in Untreated Melanoma. N Engl J Med 373:23-34. doi:10.1056/NEJMoa1504030

6. Weber JS, D'Angelo SP, Minor D et al (2015) Nivolumab versus chemotherapy in patients with advanced melanoma who progressed after anti-CTLA-4 treatment (CheckMate 037): a randomised, controlled, open-label, phase 3 trial. Lancet Oncol 16:375-384. doi:10.1016/S1470-2045(15)70076-8

7. Verdegaal EM (2016) Adoptive cell therapy: a highly successful individualized therapy for melanoma with great potential for other malignancies. Curr Opin Immunol 39:90-95. doi:10.1016/j.coi.2016.01.004

8. Bol KF, van den Bosch T, Schreibelt G et al (2016) Adjuvant Dendritic Cell Vaccination in High-Risk Uveal Melanoma. Ophthalmology 123:2265-2267. doi:10.1016/j.ophtha.2016.06.027

9. de la Cruz PO Jr, Specht CS, McLean IW (1990) Lymphocytic infiltration in uveal malignant melanoma. Cancer 65:112-115

10. Whelchel JC, Farah SE, McLean IW, Burnier MN (1993) Immunohistochemistry of infiltrating lymphocytes in uveal malignant melanoma. Invest Ophthalmol Vis Sci 34:2603-2606

11. de Waard-Siebinga I, Hilders CG, Hansen BE, van Delft JL, Jager MJ (1996) HLA expression and tumor-infiltrating immune cells in uveal melanoma. Graefes Arch Clin Exp Ophthalmol 234:34-42 
12. Ericsson C, Seregard S, Bartolazzi A, Levitskaya E, Ferrone S, Kiessling R, Larsson O (2001) Association of HLA class I and class II antigen expression and mortality in uveal melanoma. Invest Ophthalmol Vis Sci 42:2153-2156

13. Maat W, Ly LV, Jordanova ES, de Wolff-Rouendaal D, SchalijDelfos NE, Jager MJ (2008) Monosomy of chromosome 3 and an inflammatory phenotype occur together in uveal melanoma. Invest Ophthalmol Vis Sci 49:505-510. doi:10.1167/ iovs.07-0786

14. Prescher G, Bornfeld N, Hirche H, Horsthemke B, Jockel KH, Becher R (1996) Prognostic implications of monosomy 3 in uveal melanoma. The Lancet 347:1222-1225

15. Coupland SE, Lake SL, Zeschnigk M, Damato BE (2013) Molecular pathology of uveal melanoma. Eye (Lond) 27:230 242. doi:10.1038/eye.2012.255

16. Damato B, Duke C, Coupland SE, Hiscott P, Smith PA, Campbell I, Douglas A, Howard P (2007) Cytogenetics of uveal melanoma: a 7-year clinical experience. Ophthalmology 114:1925-1931. doi:10.1016/j.ophtha.2007.06.012

17. Cassoux N, Rodrigues MJ, Plancher C et al (2014) Genomewide profiling is a clinically relevant and affordable prognostic test in posterior uveal melanoma. Br J Ophthalmol 98:769774. doi:10.1136/bjophthalmol-2013-303867

18. Singh AD, Tubbs R, Biscotti C, Schoenfield L, Trizzoi P (2009) Chromosomal 3 and 8 status within hepatic metastasis of uveal melanoma. Arch Pathol Lab Med 133:1223-1227. doi:10.1043/1543-2165-133.8.1223

19. de Lange MJ, van Pelt SI, Versluis M et al (2015) Heterogeneity revealed by integrated genomic analysis uncovers a molecular switch in malignant uveal melanoma. Oncotarget 6:37824-37835. doi:10.18632/oncotarget.5637

20. Versluis M, de Lange MJ, van Pelt SI, Ruivenkamp CA, Kroes WG, Cao J, Jager MJ, Luyten GP, van der Velden PA (2015) Digital PCR validates $8 \mathrm{q}$ dosage as prognostic tool in uveal melanoma. PLoS One 10:e0116371. doi:10.1371/journal. pone. 0116371

21. Tschentscher F, Husing J, Holter T et al (2003) Tumor classification based on gene expression profiling shows that uveal melanomas with and without monosomy 3 represent two distinct entities. Cancer Res 63:2578-2584

22. Onken MD, Worley LA, Ehlers JP, Harbour JW (2004) Gene expression profiling in uveal melanoma reveals two molecular classes and predicts metastatic death. Cancer Res 64:72057209. doi:10.1158/0008-5472.can-04-1750

23. Harbour JW, Onken MD, Roberson ED et al (2010) Frequent mutation of BAP1 in metastasizing uveal melanomas. Science 330:1410-1413. doi:10.1126/science. 1194472

24. Koopmans AE, Verdijk RM, Brouwer RW et al (2014) Clinical significance of immunohistochemistry for detection of BAP1 mutations in uveal melanoma. Mod Pathol 27:1321-1330. doi:10.1038/modpathol.2014.43

25. Kalirai H, Dodson A, Faqir S, Damato BE, Coupland SE (2014) Lack of BAP1 protein expression in uveal melanoma is associated with increased metastatic risk and has utility in routine prognostic testing. Br J Cancer 111:1373-1380. doi: $10.1038 /$ bjc. 2014.417

26. van Essen TH, van Pelt SI, Versluis M et al (2014) Prognostic parameters in uveal melanoma and their association with BAP1 expression. Br J Ophthalmol 98:1738-1743. doi:10.1136/bjophthalmol-2014-305047

27. Fang Y, Fu D, Shen XZ (2010) The potential role of ubiquitin c-terminal hydrolases in oncogenesis. Biochim Biophys Acta 1806:1-6. doi:10.1016/j.bbcan.2010.03.001

28. Karim R, Tummers B, Meyers C et al (2013) Human papillomavirus (HPV) upregulates the cellular deubiquitinase UCHL1 to suppress the keratinocyte's innate immune response. PLoS Pathog 9:e1003384. doi:10.1371/journal.ppat.1003384

29. Bronkhorst IH, Ly LV, Jordanova ES, Vrolijk J, Versluis M, Luyten GP, Jager MJ (2011) Detection of M2-macrophages in uveal melanoma and relation with survival. Invest Ophthalmol Vis Sci 52:643-650. doi:10.1167/iovs.10-5979

30. Bronkhorst IH, Vu TH, Jordanova ES, Luyten GP, Burg SH, Jager MJ (2012) Different subsets of tumor-infiltrating lymphocytes correlate with macrophage influx and monosomy 3 in uveal melanoma. Invest Ophthalmol Vis Sci 53:5370-5378. doi:10.1167/iovs.11-9280

31. Ly LV, Bronkhorst IH, van Beelen E, Vrolijk J, Taylor AW, Versluis M, Luyten GP, Jager MJ (2010) Inflammatory cytokines in eyes with uveal melanoma and relation with macrophage infiltration. Invest Ophthalmol Vis Sci 51:5445-5451. doi:10.1167/ iovs. 10-5526

32. Bronkhorst IH, Jehs TM, Dijkgraaf EM, Luyten GP, van der Velden PA, van der Burg SH, Jager MJ (2014) Effect of hypoxic stress on migration and characteristics of monocytes in uveal melanoma. JAMA Ophthalmol. 132: 614-621. doi:10.1001/ jamaophthalmol.2014.43

33. van den Bosch $\mathrm{T}$, Koopmans AE, Vaarwater J, van den Berg M, de Klein A, Verdijk RM (2013) Chemokine receptor CCR7 expression predicts poor outcome in uveal melanoma and relates to liver metastasis whereas expression of CXCR4 is not of clinical relevance. Invest Ophthalmol Vis Sci 54:7354-7361. doi:10.1167/iovs.13-12407

34. McCarroll SA, Kuruvilla FG, Korn JM, Cawley S, Nemesh J, Wysoker A, Shapero MH, de Bakker PIW, Maller JB, Kirby A, Elliott AL, Parkin M, Hubbell E, Webster T, Mei R, Veitch J, Collins PJ, Handsaker R, Lincoln S, Nizzari M, Blume J, Jones KW, Rava R, Daly MJ, Gabriel SB, Altshuler D (2008) Integrated detection and population-genetic analysis of SNPs and copy number variation. Nat Genet 40(10):1166-1174

35. Mermel CH, Schumacher SE, Hill B, Meyerson ML, Beroukhim R, Getz G (2011) GISTIC2.0 facilitates sensitive and confident localization of the targets of focal somatic copy-number alteration in human cancers. Genome Biol 12(4):R41

36. Van Raamsdonk CD, Griewank KG, Crosby MB et al (2010) Mutations in GNA11 in uveal melanoma. N Engl J Med 363:2191-2199. doi:10.1056/NEJMoa1000584

37. Onken MD, Worley LA, Long MD, Duan S, Council ML, Bowcock AM, Harbour JW (2008) Oncogenic mutations in GNAQ occur early in uveal melanoma. Invest Ophthalmol Vis Sci 49:5230-5234. doi:10.1167/iovs.08-2145

38. Singh N, Singh AD, Hide W (2015) Inferring an Evolutionary Tree of Uveal Melanoma From Genomic Copy Number Aberrations. Invest Ophthalmol Vis Sci 56:6801-6809. doi:10.1167/ iovs. $15-16822$

39. Royds JA, Sharrard RM, Parsons MA, Lawry J, Rees R, Cottam D, Wagner B, Rennie IG (1992) C-myc oncogene expression in ocular melanomas. Graefes Arch Clin Exp Ophthalmol 230:366-371

40. Parrella P, Caballero OL, Sidransky D, Merbs SL (2001) Detection of c-myc amplification in uveal melanoma by fluorescent in situ hybridization. Invest Ophthalmol Vis Sci 42:1679-1684

41. Borrello MG, Degl'Innocenti D, Pierotti MA (2008) Inflammation and cancer: the oncogene-driven connection. Cancer Lett 267:262-270. doi:10.1016/j.canlet.2008.03.060

42. De Waard-Siebinga I, Blom DJ, Griffioen M, Schrier PI, Hoogendoorn E, Beverstock G, Danen EH, Jager MJ (1995) Establishment and characterization of an uveal-melanoma cell line. Int J Cancer 62:155-161

43. Mantovani A, Allavena P, Sica A, Balkwill F (2008) Cancer-related inflammation. Nature 454:436-444. doi:10.1038/ nature 07205 
44. Li L, Tao Q, Jin H et al (2010) The tumor suppressor UCHL1 forms a complex with p53/MDM2/ARF to promote p53 signaling and is frequently silenced in nasopharyngeal carcinoma. Clin Cancer Res 16:2949-2958. doi:10.1158/1078-0432.ccr-09-3178

45. Yang L, Karin M (2014) Roles of tumor suppressors in regulating tumor-associated inflammation. Cell Death Differ 21:16771686. doi:10.1038/cdd.2014.131

46. Wiesner T, Murali R, Fried I, Cerroni L, Busam K, Kutzner H, Bastian BC (2012) A distinct subset of atypical Spitz tumors is characterized by BRAF mutation and loss of BAP1 expression. Am J Surg Pathol 36:818-830. doi:10.1097/ PAS.0b013e3182498be5

47. Liu J, Li F, Ping Y et al (2015) Local production of the chemokines CCL5 and CXCL10 attracts CD8 + T lymphocytes into esophageal squamous cell carcinoma. Oncotarget 6:2497824989. doi:10.18632/oncotarget. 4617

48. Li H, Alizadeh H, Niederkorn JY (2008) Differential expression of chemokine receptors on uveal melanoma cells and their metastases. Invest Ophthalmol Vis Sci 49:636-643. doi:10.1167/ iovs.07-1035

49. Li H, Yang W, Chen PW, Alizadeh H, Niederkorn JY (2009) Inhibition of chemokine receptor expression on uveal melanomas by CXCR4 siRNA and its effect on uveal melanoma liver metastases. Invest Ophthalmol Vis Sci 50:5522-5528. doi:10.1167/ iovs.09-3804

50. Spranger S, Bao R, Gajewski TF (2015) Melanoma-intrinsic beta-catenin signalling prevents anti-tumour immunity. Nature 523:231-235. doi:10.1038/nature14404

51. Zuidervaart W, Pavey S, van Nieuwpoort FA, Packer L, Out C, Maat W, Jager MJ, Gruis NA, Hayward NK (2007) Expression of Wnt5a and its downstream effector beta-catenin in uveal melanoma. Melanoma Res 17:380-386. doi:10.1097/ CMR.0b013e3282f1d302

52. Vu TH, Bronkhorst IH, Versluis M, Marinkovic M, van Duinen SG, Vrolijk J, Luyten GP, Jager MJ (2013) Analysis of inflammatory cells in uveal melanoma after prior irradiation. Invest Ophthalmol Vis Sci 54:360-369. doi:10.1167/iovs.12-9424

53. Dogrusoz M, Kroes WG, van Duinen SG, Creutzberg CL, Versluis M, Bleeker JC, Marinkovic M, Luyten GP, Jager MJ (2015) Radiation treatment affects chromosome testing in uveal melanoma. Invest Ophthalmol Vis Sci 56:5956-5964. doi:10.1167/ iovs.15-17092 